\title{
Gas Chromatography aided Mass Spectral Fingerprinting of Volatile Phytoconstituents from
}

Torilis leptophylla Roots

\author{
Noshin Nasreen (noshinnasreen@yahoo.com) \\ Nabil Semmar (nabilsemmar@yahoo.fr) ${ }^{\mathrm{b}}$, \\ Muhammad Farman(farman@qau.edu.pk $)^{a^{*}}$, \\ Naseem Saud Ahmad(saudahmad@uhs.edu.pk) \\ ${ }^{a}$ Quaid-i-Azam University, Islamabad-45320,Pakistan
}

${ }^{b}$ Department of Bioinformatics, Biomathematics \& Biostatistics, University of Tunis El Manar, Tunis, Tunisia

${ }^{c}$ Department of Pharmacology, SM\&D College, University of Health Sciences, Lahore, Pakistan

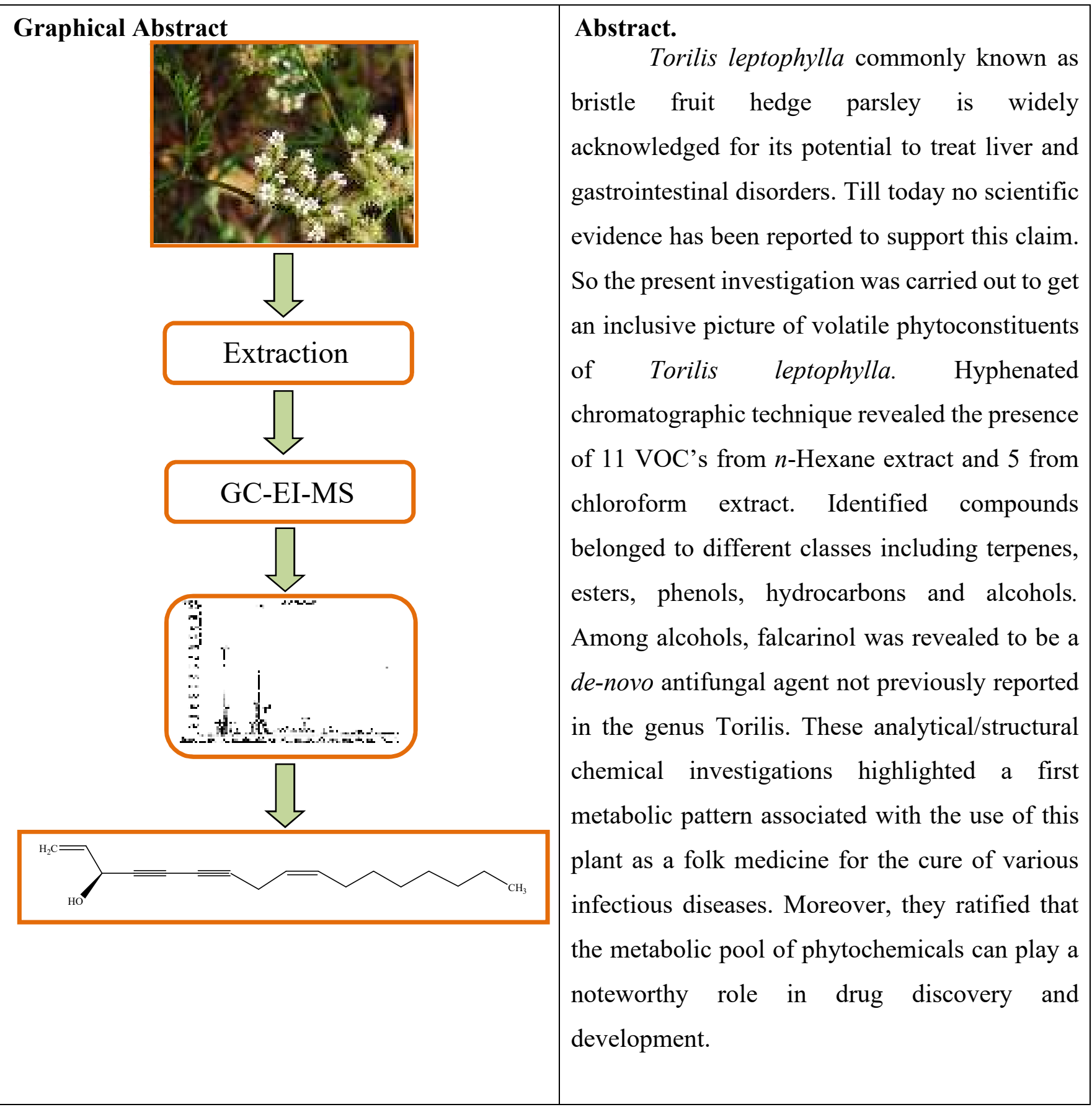




\section{Introduction}

Torilis leptophylla is commonly known as 'bristle fruit hedge parsley' due to its spine bearing fruits and wide spread along hedges. Torilis leptophylla is endemic annual herb to the Indo-Pak subcontinent and shows diversified habitats including man-made places, disturbed habitats, rocks, pastures and fields [1]. It is used since ancient times to relieve hepatic, gastric and intestinal disorders. The plant also serves as a disinfectant, so it is highly efficacious against some pathogens [2]. Furthermore, leaves are taken as vegetable while stem and branches serve as fodder [3].

Phytochemical profile of Torilis leptophylla roots has not been documented earlier. Understanding full medicinal prospects of Torilis leptophylla roots requires a complete/wide picture of its phytoconstituents. The present study aimed at exploration of volatile phytoconstituents through gas chromatography mass spectrometry (GC-MS) to provide authentic basis for medicinal usage of plant.

\section{Materials and Methods}

Roots extracts of Torilis leptophylla were prepared employing infusion technique by soaking $100 \mathrm{~g}$ of roots in $300 \mathrm{~mL} n$-hexane and chloroform respectively. Contents were irradiated at a frequency $37 \mathrm{KHz}$ and effective ultrasonic power of 80 watts by using Elma Ultrasonic LC-30H instrument for a period of 30 minutes and then kept at room temperature for 24 hours. After that infusions were filtered and the process was repeated thrice. Combined supernatants were evaporated to dryness in vacuo using Heidolph 4000-efficient rotary evaporator. Finally, crude extracts with syrupy consistency were obtained [4].

Separation of volatile phytoconstituents was carried out using Agilent technologies gas chromatographic instrument with model number $6890 \mathrm{~N}$. $5 \mu \mathrm{L}$ sample was injected manually with an injection pressure of 60-85 p.s.i. Helium was used as a carrier gas. Agilent JW Scientific DB-5MS column having dimensions $30 \mathrm{~m} \mathrm{X} 0.25 \mathrm{~mm}$ i.d. X $0.25 \mu \mathrm{m}$ film thickness was used. Ramping temperature was $120-280^{\circ} \mathrm{C}$ with regular increase of $12^{\circ} \mathrm{C}$ per min. For mass spectral profiling Agilent mass spectrometer 5973 was used. Ionization mode was electron impact and ionization potential of $70 \mathrm{eV}$ was applied. Ions were sorted by Quadruple analyzer and detected by photomultiplier.

Clear and concentrated Torilis leptophylla $n$-Hexane (TLH) and Torilis leptophylla chloroform (TLC) extracts were submitted to GC-EI-MS analysis.

\section{Results and Discussion}

GC-MS analysis revealed the presence of 11 and 5 VOCs from TLH and TLC, respectively. They belonged to different classes of compounds including terpenes, esters, phenols and hydrocarbons. Identity of the compounds was established on the basis of literature cited [5]. The molecular formula of the compounds was deduced from their corresponding molecular masses by applying rule of thirteen. Evidences obtained from the mass spectra for the presence of heteroatom(s) were used to modify the base formulae. The degree of unsaturation was identified by using Hydrogen deficiency index (HDI). Total ion current chromatograms of the $n$-Hexane and chloroform extracts are shown in 1 and 2 respectively. 


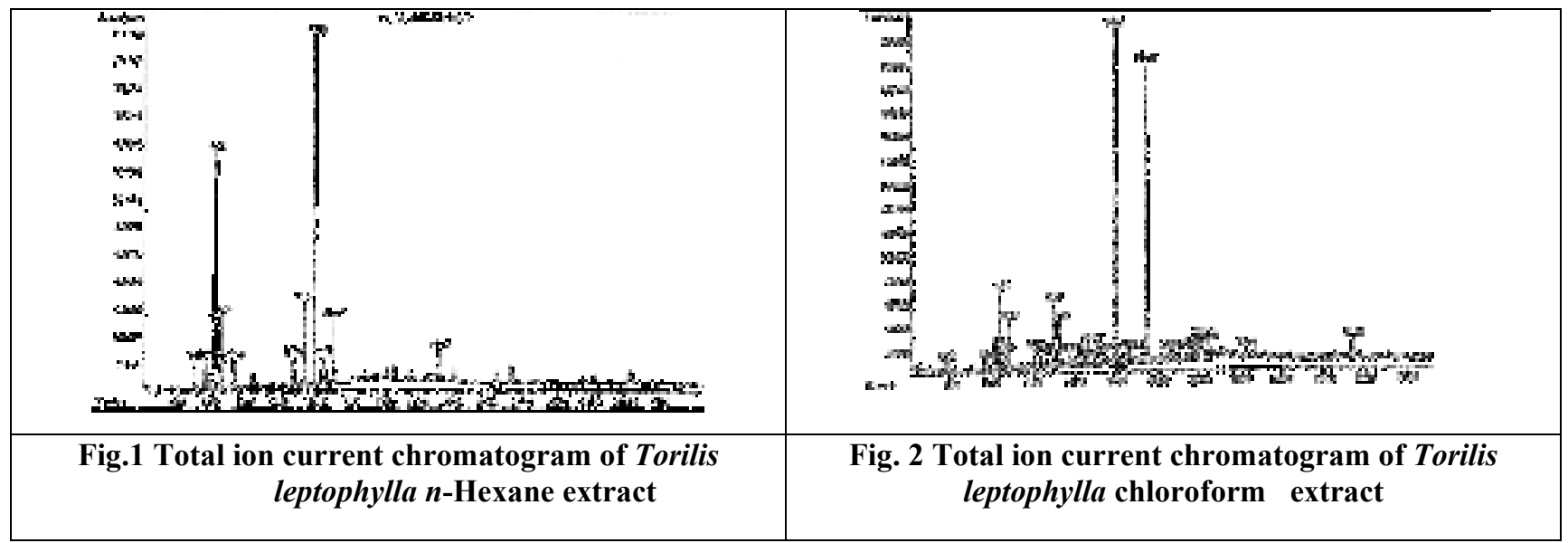

\section{Compound TLH-1}

The TIC for the compound was $5.073 \mathrm{~min}$. The mass spectrum observed for the compound contained pronounced peaks at m/z 204, 161, 133, 119, 105, 91 and 55. At m/z lower than 204, some other peaks of considerable intensity were also observed. Co-eluted compounds, contaminated ion source and bleeding of column stationary phase resulted in the appearance of relatively smaller intensity signals at $\mathrm{m} / \mathrm{z}$ higher than 204.

Molecular ion peak was observed at m/z 204 and was quite abundant. This abundance was correlated with the structure of the compound. The abundance of molecular ion peak showed that there was only a little congestion within the molecule. Furthermore, the molecular ion was even suggesting that either nitrogen was absent or even number of nitrogen atoms were there in the compound TLH-1. Base peak was observed at m/z 161 formed by the loss of 43 mass units corresponding to the loss of propyl radical. The peak at $\mathrm{m} / \mathrm{z} 55$ was quite abundant and absence of ion corresponding to 149 mass units provided ample information for the presence of cyclohexane ring system in the compound.

To assist already manifested evidences, explanation of diagnostic signal is given below.

\begin{tabular}{|c|l|l|}
\hline \multicolumn{3}{|c|}{ Interpretation of Diagnostic Signals } \\
\hline Signals at $\mathbf{m} / \mathbf{z}$ & Indicator & Interpretation \\
\hline 55 & Allylic cleavage & Double bond \\
\hline
\end{tabular}

Deductions from the lost fragments towards the sanction of actual structure are presented below

\begin{tabular}{|l|l|l|}
\hline \multicolumn{3}{|c|}{ Deductions from lost fragments } \\
\hline Differences in $\mathrm{m} / \mathrm{z}$ & Deductions & Interpretation \\
\hline
\end{tabular}




\begin{tabular}{|l|l|l|}
\hline $204-189=15$ & Loss of methyl radical & $\begin{array}{l}\text { Branched or Cyclic } \\
\text { system }\end{array}$ \\
\hline $204-161=43$ & Loss of propyl radical & $n$-propyl or isopropyl \\
\hline $161-133=28$ & Loss of ethane & \multirow{2}{*}{ Ring system } \\
\hline $133-105=28$ & Loss of ethane & \\
\hline $161-119=42$ & Loss of cyclopropane & Ring system \\
\hline
\end{tabular}

\section{Rule of Thirteen $\mathrm{C}_{15} \mathrm{H}_{24}$}

Molecular formula of the compound was determined to be $\mathrm{C}_{15} \mathrm{H}_{24}$ by applying rule of thirteen. $\mathrm{C}_{15} \mathrm{H}_{24}$ is a multiple of $\mathrm{C}_{5} \mathrm{H}_{8}$ that depicted 2-methyl-1,3-butadiene also called isoprene unit in the compound. The presence of isoprene unit provided vital clue that the compound belonged to the terpenes class of secondary metabolites more precisely to the sesquiterpenes [6].

\section{Modified formulaC ${ }_{15} \mathrm{H}_{24}$}

As there was no indication for the presence of heteroatom, modified formula was the same as the base formula.

\section{Hydrogen deficiency index 4}

HDI was calculated to be 4 which could be justified by any of the given ways.

$\begin{array}{ll}\text { Possibilities } & 3 \text { double bonds }+1 \text { ring } \\ & 4 \text { double bonds } \\ & 1 \text { triple bond }+2 \text { double bonds } \\ & 2 \text { double bonds }+2 \text { rings } \\ & 3 \text { rings }+1 \text { double bond }\end{array}$

First and second possibilities were ruled out because the compound belonged to the terpenes class. Third possibility was excluded because no signal was observed for propargylic cleavage at $\mathrm{m} / \mathrm{z}$ 39 or at higher homologues of 39, indicated absence of triple bond in the compound. Fourth possibility was excluded because of the absence of the signal at even $\mathrm{m} / \mathrm{z} 54$ corresponding to Retro Diels-Alder cleavage. One possibility was left for adjusting HDI of 4, one double bond and 3 rings in the compound.

\section{Proposed structure}

By joining all the above mentioned patches structure of the compound was proposed as $\alpha$ cubebene.<smiles>CC1=CC2CC3(C1)[C@@H](C)CCC(C(C)C)C23C</smiles>

Structure of $\alpha$-cubebene

\section{Fragmentation Scheme}


For the justification of major fragments formed in EI-MS, fragmentation scheme of the compound in detail is given in scheme 1.

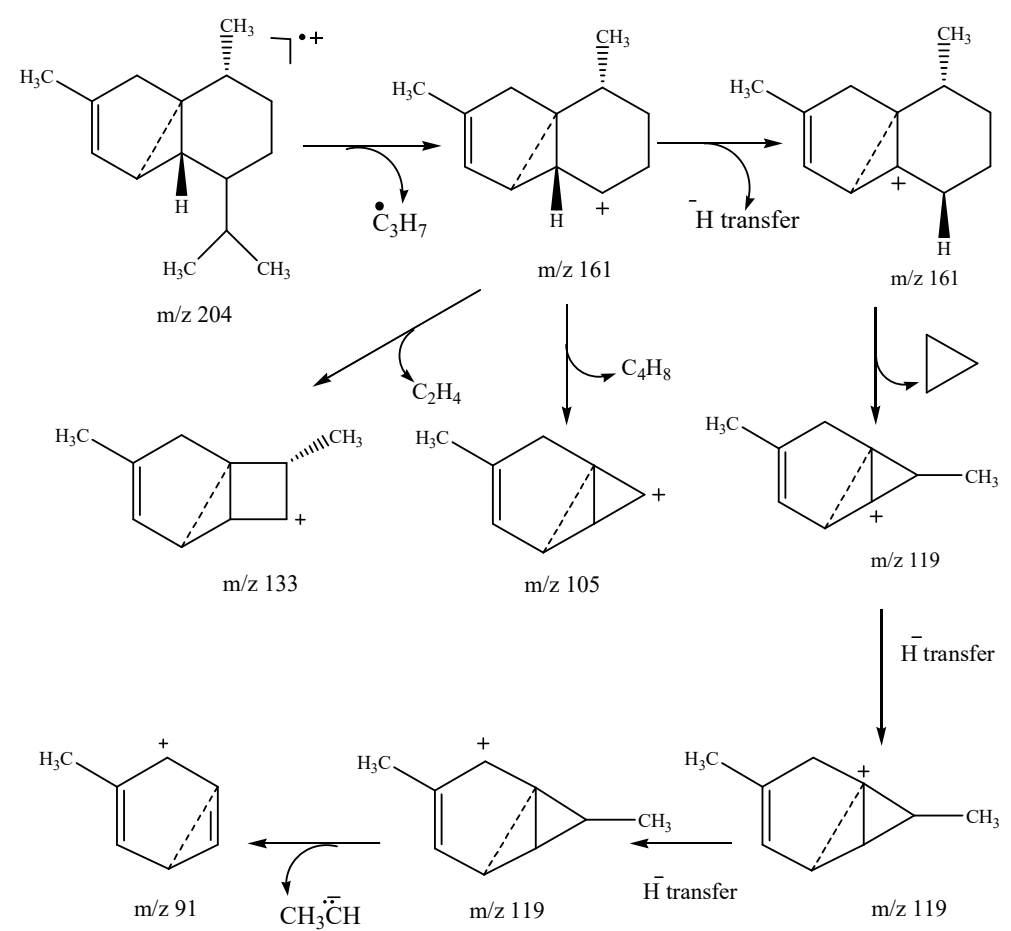

Scheme 1Fragmentation scheme of $\alpha$-cubebene

The low intensity signal at $\mathrm{m} / \mathrm{z} 189$ suggested the loss of methyl radical from molecular ion at $\mathrm{m} / \mathrm{z} 204$. As methyl group is not readily lost from acyclic system so it suggested that it was present as branch at cyclic or acyclic system or at bridge head position. The stability of this peak was associated with the formation of secondary carbocation that rearranges to tertiary carbocation by a hydride transfer. The intensity of peak at m/z 119 is a little less than that of base peak; the fragment that portrayed $\mathrm{m} / \mathrm{z}$ 119 not only contained an internal alkene but also had a secondary carbocation that was in resonance which favored the increased stability of this fragment.

The peak at m/z 133 was formed by the loss of twenty eight mass units from the fragment corresponding to $\mathrm{m} / \mathrm{z} 161$. The loss of twenty eight mass units corresponded either to the loss of ethene molecule or loss of carbonyl. The driving force for the formation of peak at m/z 105 was due to the loss of neutral molecule of methyl cyclopropane corresponding to the loss of 56 mass units from the fragment of mass 161. The abundance of signal at m/z 119 was diagnostic between two isomers of Cubebene. In case of $\alpha$-Cubebene, this signal was of higher abundance whereas in case of $\beta$-Cubebene, it showed comparatively lower intensity. The reason for stability was the same in both cases that was the presence of double bond in conjugation with secondary carbocation. Difference was due to alkene which was more and less substitutedin the first and second cases, respectively. 
Compound TLH-8: Compound eluted at $11.918 \mathrm{~min}$. Molecular ion was observed at $\mathrm{m} / \mathrm{z} 244$. Even molecular ion suggested that either nitrogen was absent or even number of nitrogen were there in the compound. A number of fragments were observed in the mass spectrum corresponding to $\mathrm{m} / \mathrm{z} 159, \mathrm{~m} / \mathrm{z}$ 141, $\mathrm{m} / \mathrm{z} 133, \mathrm{~m} / \mathrm{z} 139, \mathrm{~m} / \mathrm{z} 119, \mathrm{~m} / \mathrm{z} 91$ and $\mathrm{m} / \mathrm{z} 55$. The negligible intensity of molecular ion peak suggested increased congestion in the compound. Base peak was observed at $\mathrm{m} / \mathrm{z} 55$. Bell shaped pattern unveiled the presence of long chain alkyl moiety in the compound.

Interpretation of the lost fragments is given below.

\begin{tabular}{|l|l|l|}
\hline \multicolumn{3}{|c|}{ Deductions from lost fragments } \\
\hline Losses in m/z & Deduction & Interpretation \\
\hline $119-101=18$ & Loss of water molecule & $\begin{array}{l}\text { Alcohol or phenol } \\
\text { moiety }\end{array}$ \\
\hline $\begin{array}{l}\text { Sequential losses of } 14 \\
\text { mass units }\end{array}$ & Loss of methylene & $\begin{array}{l}\text { Longer chain alkyl } \\
\text { part }\end{array}$ \\
\hline
\end{tabular}

Interpretation of diagnostic signals for the endorsement of actual structure is given below.

\begin{tabular}{|c|l|}
\hline \multicolumn{2}{|c|}{ Interpretation of diagnostic signals } \\
\hline Signals at $\mathbf{m} / \mathbf{z}$ & Interpretation \\
\hline 55 & Allylic cleavage \\
\hline 119 & Higher homologue of propargylic cleavage. \\
\hline 139 & Higher homologue of allylic cleavage \\
\hline
\end{tabular}

\section{Base FormulaC ${ }_{17} \mathrm{H}_{40}$}

Base formula was determined by applying rule of thirteen to be $\mathrm{C}_{17} \mathrm{H}_{40}$.

Modified formulaC ${ }_{17} \mathrm{H}_{24} \mathrm{O}$

Base formula was modified for the presence of one oxygen atom.

Hydrogen Deficiency Index 6

$\begin{array}{ll}\text { Possibilities } & 6 \text { double bonds } \\ & 3 \text { triple bonds } \\ & 1 \text { triple bond }+4 \text { double bonds } \\ & 2 \text { triple bonds }+2 \text { double bonds }\end{array}$

The possibilities that included the ring(s) were excluded because no evidence for ring has been detected. On the basis of diagnostic signals, the first three possibilities of HDI were ruled out so left with just one possibility ( 2 triple bonds +2 double bonds).

\section{Proposed structure}

On the basis of above-mentioned evidences, structure of compound TLH- 8 was proposed as Falcarinol. 


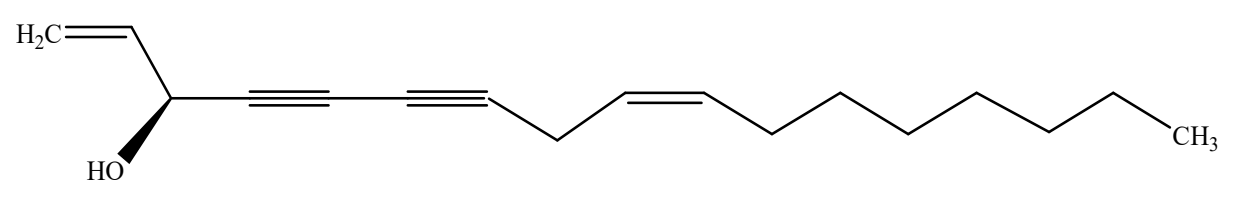

Structure of Falcarinol

\section{Proposed fragmentation scheme}

For the rationalization of major EI-MS fragments, proposed fragmentation pattern is shown in scheme $2 \mathrm{a}$.
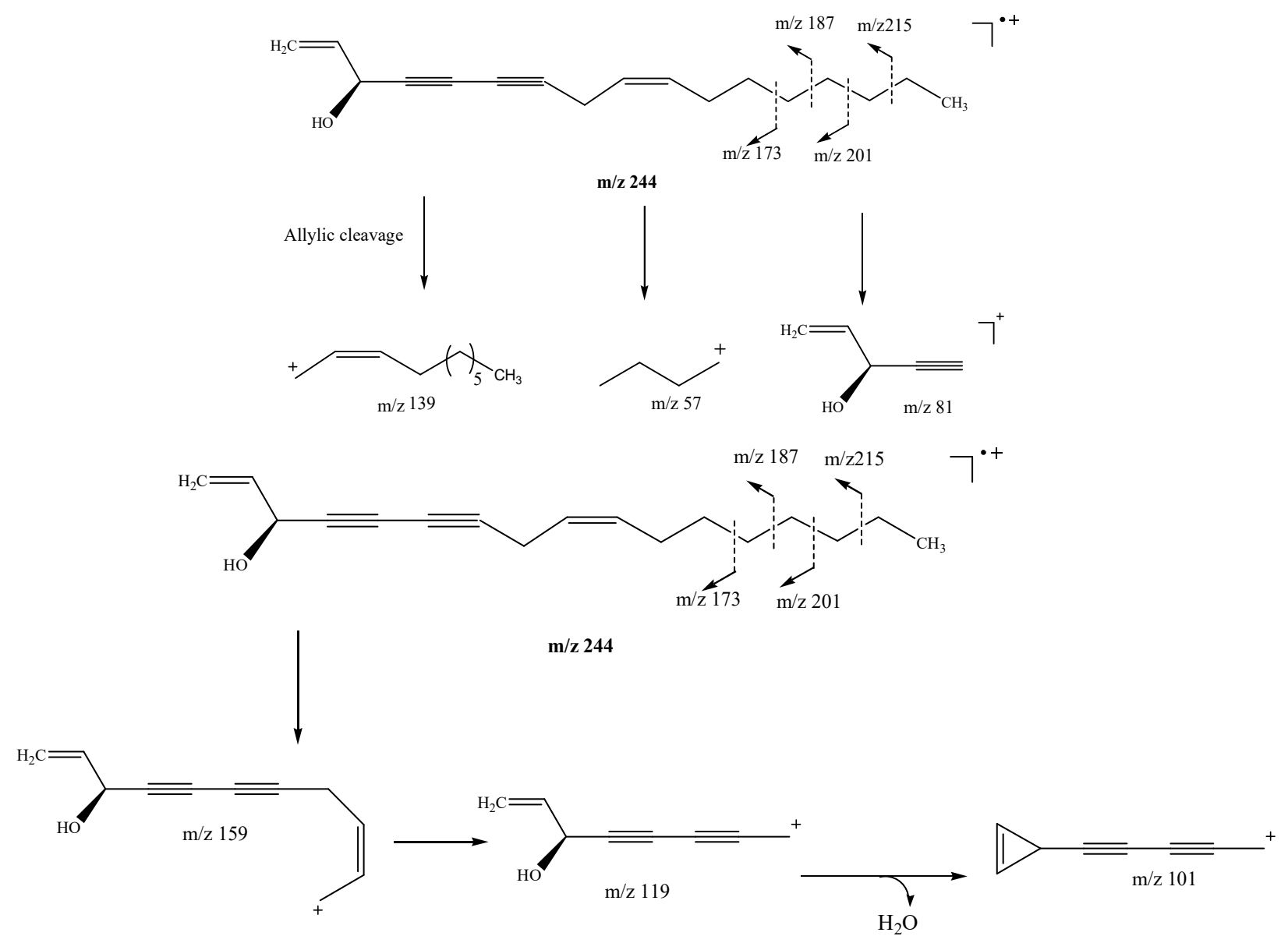

Scheme 2a Fragmentation scheme of Falcarinol

Bell shaped pattern, sequential losses of 14 mass units (corresponding to $\mathrm{m} / \mathrm{z} 215, \mathrm{~m} / \mathrm{z} 201, \mathrm{~m} / \mathrm{z} 187$ and $\mathrm{m} / \mathrm{z}$ 173) continuously reducing intensity while moving from higher $\mathrm{m} / \mathrm{z}$ to lower $\mathrm{m} / \mathrm{z}$ suggested the presence of alkane or long chain alkyl parts. Base peak was observed at $\mathrm{m} / \mathrm{z} 55$. The fragment corresponding to this $\mathrm{m} / \mathrm{z}$ was formed by the loss of neutral molecule of $\mathrm{H}_{2}$ gas from secondary carbocation. Reason for the stability of this fragment was resonance stabilized carbocation. Carbocation rearrangement in Falcarinol is given in scheme $2 b$.<smiles>CCC(C)C</smiles>

$\mathrm{m} / \mathrm{z} 57$

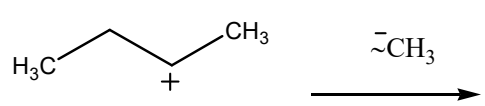

$\mathrm{m} / \mathrm{z} 57$<smiles>[CH2+]C(C)C</smiles>

$\mathrm{m} / \mathrm{z} 57$

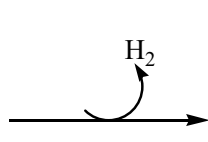<smiles>C=C([CH2-])C</smiles>

$\mathrm{m} / \mathrm{z} 55$

Scheme 2bCarbocation rearrangement in Falcarinol 
Allylic cleavage led to the formation of fragment corresponding to $\mathrm{m} / \mathrm{z} 159$. Loss of 18 mass units corresponding to loss of water molecule from the fragment of $\mathrm{m} / \mathrm{z} 159$ resulted in formation of fragment at $\mathrm{m} / \mathrm{z} 141$.

Fragment at m/z 119 was formed from fragment corresponding to $\mathrm{m} / \mathrm{z} 159$ as a result of Propargylic cleavage and loss of water molecule from this fragment leading to a peak at $\mathrm{m} / \mathrm{z} 101$. On the basis of above mentioned evidences the structure of the compound was proposed as falcarinol [7].

\section{List of identified compounds based upon GC-MS analyses}

Identified compounds from GC-MS analysis of TLH and TLC extract are tabulated below.

\section{Table 1 Identified compounds from TLH and TLC extracts}

\begin{tabular}{|c|c|c|c|c|c|c|c|}
\hline $\begin{array}{l}\text { Sr. } \\
\text { No. }\end{array}$ & $\begin{array}{c}\text { Compd. } \\
\text { Code }\end{array}$ & $\begin{array}{l}\text { TIC } \\
\text { (min.) }\end{array}$ & $\begin{array}{l}\text { Peak } \\
\text { area }\end{array}$ & $\begin{array}{c}\text { Relative } \\
\text { peak } \\
\text { area } \\
(\%)\end{array}$ & $\mathrm{m} / \mathrm{z}$ of Prominent peaks & $\begin{array}{c}\text { Mol. } \\
\text { weight } \\
\text { (a.m.u) }\end{array}$ & Identity \\
\hline 1 & TLH-1 & 5.073 & 755471 & 7.09 & $204, \mathbf{1 6 1}, 133,119,105,91,55$ & 204 & $\alpha$-Cubebene \\
\hline 2 & TLH-2 & 5.602 & 879609 & 8.26 & $204,189,161,133,93,69$ & 204 & Caryophyllene \\
\hline 3 & TLH-3 & 5.702 & 942577 & 8.85 & $248,189,161,133,93,69$ & 248 & $\begin{array}{c}\text { 6,10-dimethyl-2-methylene-5- } \\
\text { propoxy bicyclo[7.2.0] } \\
\text { undecane }\end{array}$ \\
\hline 4 & TLH-4 & 6.256 & 6972951 & 65.46 & $204, \mathbf{1 6 1}, 133,119,105,91,55$ & 204 & $\beta$-Cubebene \\
\hline 5 & TLH-5 & 6.357 & 2871104 & 26.95 & $206,191,163,141,115,91,57$ & 206 & $\begin{array}{l}\text { 2,4-bis 1,1-di methyl ethyl } \\
\text { phenol }\end{array}$ \\
\hline 6 & TLH-6 & 6.591 & 2184325 & 20.51 & $204,189, \mathbf{1 6 1}, 119,105,91$ & 204 & $\delta$-cadinene \\
\hline 7 & TLH-7 & 11.381 & 2659328 & 24.97 & $284,241,157, \mathbf{8 8}, 55$ & 284 & Ethyl palmitate \\
\hline 8 & TLH-8 & 11.918 & 1065171 & 100 & $244,173,159,141,115,91,55$ & 244 & Falcarinol \\
\hline 9 & TLH-9 & 12.371 & 891521 & 8.37 & $208,165,123,95,105,67$ & 208 & $\begin{array}{l}\text { 2-isopropyl-9,10-dimethyl } \\
\text { hexahydro naphthalene }\end{array}$ \\
\hline 10 & TLH-10 & 12.95 & 1794445 & 16.85 & $\begin{array}{c}308,263,191,164,137,121,57 \\
95,67\end{array}$ & 308 & Ethyl linoleate \\
\hline 11 & TLH-11 & 19.183 & 2043466 & 19.18 & $208,109,96,57$ & 208 & 1-cyclohexyl non-1-ene \\
\hline 12 & TLC-1 & 6.35 & 168261 & 33.85 & $57,91,135, \mathbf{1 9 1}, 206$ & 206 & Muurol-5-ene-4-one \\
\hline 13 & TLC-2 & 10.72 & 50738 & 10.21 & $\mathbf{7 4}, 115,143,185,241,270$ & 270 & Methyl hexadecanoate \\
\hline 14 & TLC-3 & 10.27 & 77038 & 15.50 & $109,152,156, \mathbf{1 9 5}, 224$ & 224 & Vinbarbital \\
\hline 15 & TLC-4 & 6.59 & 25616 & 5.15 & $91, \mathbf{1 0 5}, 118,134,161,204$ & 204 & Guai-3,9-diene \\
\hline 16 & TLC-5 & 6.78 & 79953 & 16.08 & $55,77,115,137,177, \mathbf{2 0 8}$ & 208 & Crocatone \\
\hline
\end{tabular}

\section{Conclusions}


Identification of these important biologically active compounds revealed that $T$. leptophylla is a promising source of noteworthy bioactive compounds that could be utilized in future for the development of new and safer drugs.

\section{References}

[1] Flora of Pakistan http://www.efloras.org/florataxon.aspx?flora id=5\&taxon id=133141

[2] Maleki S, Seyyednejad SM, Damabi NM, Motamedi H. Antibacterialactivity of the fruits of Iranian Torilis leptophylla against some clinical pathogens. Pak J Biol Sci. 2008; 11: 1286-1289.

[3] Abbasi AM, Shah MH, Khan MA. Wild edible vegetables of lesser Himalayas. Ethnobotanical and neutraceutical aspects. Springer international Publishing, Switzerland; 2014: 131-132.

[4]Nasreen N, Semmar N, Farman M, Ahmad NS. Employment of hyphenated approach for metabolomics fingerprinting of phenolics from Torilis leptophylla roots 2018.

[5]Masoudi S, Taherkhani M, Valadkhani Z, Baradari T, Cheraghi M. Rustaiyan AH. Volatile Constituents of the Aerial Parts of Torilis leptophylla (L.) Reichenb, Theococarpus meifolious Boiss., Leaves of Xanthogalum purpurascens Ave.Lall. and Flowers of Astrodaucus orientalis (L.) Drude. Four Umbelliferae Herbs from Iran. Journal of Essential oil Bearing Plants 2011; 6: 934-942.

[6] von Sydow, ERIK. Mass spectrometry of Terpenes. Acta Chemica Scandinavica 1965; 19: 2083 2088.

[7] Mercier J, Ponnampalam R, Bérar LS, Arul J. Polyacetylene content and UV-induced 6methoxymellein accumulation in carrot cultivars. Journal of the Science of Food and Agriculture 1993; 63: 313-317. 